\title{
Seat restraint use, previous driving history, and non-fatal injury: quantifying the risks
}

\author{
K M Venkat Narayan, D Ruta, T Beattie
}

\begin{abstract}
Aims-To quantify the increased risk of non-fatal injury when children travel unrestrained in a car, and to identify other preventable risk factors.

Methods-Case-control study of 78 children presenting to an accident and emergency (A\&E) department having sustained an injury while travelling in a car, and 97 children attending an $A \& E$ outpatient clinic with conditions unrelated to road traffic accidents.

Results-Seat restraint was associated with a $93 \%$ lower risk of child accident injury. A driver with points on the licence was over five times more likely to have had an accident resulting in child injury than a driver without points. Child accident injury was also associated with the driver's accident history.

Conclusions-These data allow the effect of achieving new target levels of seat restraint use to be estimated. Strategies aimed at reducing the risk of further accident among drivers with a history of accident may have a beneficial impact on childhood accident injuries. (Arch Dis Child 1997;77:335-338)
\end{abstract}

Keywords: seat restraint; road traffic accident; injury

Road traffic accidents (RTAs) are a major cause of death and injury to children, ${ }^{1}$ and account for a quarter of all deaths in those of schoolgoing age in the United Kingdom. ${ }^{1}$ Of those children killed or seriously injured in a road traffic accident, $16 \%$ are car passengers, ${ }^{2}$ and $10 \%$ of all fatal injuries to children occur in this group. ${ }^{3}$ Promotion of child seat restraint use is an important part of the government's strategy for reducing mortality from accidents among children under the age of 15 years, ${ }^{4}$ and free loan of restraints has been shown to increase restraint use. ${ }^{56}$ However, few data exist on the effectiveness of seat restraint use, and those that do are mostly based either on changes in national accident trends following seat restraint legislation ${ }^{7}$ or on epidemiological studies that may have suffered from selection bias ${ }^{910}$ or confounding. ${ }^{112}{ }^{12}$ We report a case-control study of the effectiveness of seat restraint use, which was designed to overcome some of these shortcomings, to quantify the increased risk of non-fatal injury to which children are exposed when they travel unrestrained in a car, and to identify any other potentially preventable risk factors.

\section{Methods \\ CASES}

Cases were all 78 children aged 13 years and under presenting to the accident and emergency (A\&E) department at the Royal Aberdeen Children's Hospital with injuries sustained in a RTA while travelling as a passenger between December 1989 and November 1990. Maximum abbreviated injury score (MAIS) ${ }^{13}$ and type of injury were assessed by an A\&E consultant (TB) and all cases had an MAIS of $>0$. No fatal injury occurred during the study period. Data on seat restraint use, time of accident, and age and sex of child were also obtained. Additional data on cases were obtained from a parent of the child. A structured telephone interview was conducted and the following items of information were collected: age, sex, age on leaving full time education, housing tenure, and employment status of interviewee; length of journey, time of journey, history of previous motoring accidents or offences by the driver.

Forty cases were contacted and all consented to the interview. The remainder were not registered in the telephone directory, had moved, or were not contactable after at least three attempts.

\section{CONTROLS}

Parents of children aged 13 years and under attending the A\&E outpatient clinic with any condition unrelated to a road traffic accident were interviewed. All controls were independent of the cases, that is, from separate families. Data pertaining to the last car journey, similar to those collected for cases, were obtained for each child attending the clinic and for any sibling aged 13 years. Approximately 2.5 controls per case with complete information were recruited to enhance the power of the study; 97 controls were thus identified.

RANDOM RESPONSE TECHNIQUE

Because seat restraint may be perceived as desirable and because legislation was in force making unrestrained travel an offence, parents of controls may be inclined to report restraining when in truth the child was unrestrained. This kind of information bias, to give a socially acceptable response, has been documented in other sensitive situations like cot death and sleeping position. ${ }^{14}$ To assess whether such an information bias was a problem in the present study, we used a survey method called the random response technique (RRT), ${ }^{15}$ which is designed to encourage respondents to give the true answer, and applied it to a third group of controls. The estimate of the prevalence of seat 
Table 1 Characteristics of cases and controls

\begin{tabular}{|c|c|c|c|}
\hline & Cases $(n=40)$ & Controls $(n=97)$ & $p$ Value ${ }^{\star}$ \\
\hline Child restrained (yes) (\%) & 60.0 & 95.9 & $<0.001$ \\
\hline Sex of parent (male) (\%) & 52.5 & 47.4 & 0.590 \\
\hline Driver (\%) & & & $<0.01$ \\
\hline Interviewee & 47.5 & 73.2 & \\
\hline Interviewee's spouse & 35.0 & 19.6 & \\
\hline Relative, friend, others & 17.5 & 17.2 & \\
\hline Journey time $(\%)$ & & & $<0.001$ \\
\hline $6 \mathrm{am}-12$ noon & 25.0 & 69.1 & \\
\hline 12 noon- $6 \mathrm{pm}$ & 52.5 & 28.9 & \\
\hline $6 \mathrm{pm}-6 \mathrm{am}$ & 22.5 & 2.1 & \\
\hline Journey length (miles) (\%) & & & $<0.05$ \\
\hline$<1$ & 5.0 & 25.8 & \\
\hline $1-5$ & 25.0 & 26.8 & \\
\hline $5-10$ & 35.0 & 26.8 & \\
\hline$\geqslant 10$ & 35.0 & 20.6 & \\
\hline Marital status (married) (\%) & 85.0 & 89.7 & 0.439 \\
\hline Employment (\%) & & & $<0.05$ \\
\hline Full time & 45.0 & 23.7 & \\
\hline Part time & 25.0 & 27.8 & \\
\hline Retired, student, unemployed & 30.0 & 48.5 & \\
\hline Housing (own) (\%) & 67.5 & 65.0 & 0.776 \\
\hline Points on licence (yes) (\%) & 35.0 & 9.3 & $<0.001$ \\
\hline No of points $\dagger$ & $0.93(0.28)$ & $0.18(0.07)$ & $<0.01$ \\
\hline No of accidents in 5 yearst & $1.03(0.14)$ & $0.20(0.05)$ & $<0.001$ \\
\hline $\begin{array}{l}\text { Age at completion of full time education } \\
\text { (years) } \dagger\end{array}$ & $17.4 \quad(0.38)$ & $17.7 \quad(0.39)$ & 0.551 \\
\hline
\end{tabular}

$\mathrm{p}$ Values comparing cases with controls.

†Figures are mean (SE).
Because of small sample sizes, data on cases and controls were pooled to assess associations of potential confounding variables with seat restraint, and these are presented in table 2 . There were no significant interactions between being a case or control and any of the independent variables on the effect of seat restraint use. Therefore the pooled estimates are unlikely to have any inherent bias. Journey time, journey length, driver having points on the licence, and driver's marital status and housing status were all associated with reported seat restraint use ( $\mathrm{p}<0.05$ for each), but driver's gender and employment status were not. Table 3 shows the results of multiple logistic regression analysis, where each odds ratio is controlled for all other factors in the table. Thus, controlled for potential confounding factors, a restrained child was $93 \%$ less likely to have suffered an injury than an unrestrained child. Journeys between $6 \mathrm{pm}$ and 6 am were over 30 times more likely to be associated with child injury than journeys between 6 am and noon, journeys 10 miles or longer were nearly nine times more likely to be associated with child injury than journeys less than one mile in length. Child injury was also associated with the driver's accident historydrivers with points on their licence were over five times more likely to have had an accident resulting in child injury than drivers without points, and the risk of child injury increased with the number of points on the license.

Table 4 shows the significant predictors identified from a stepwise logistic regression model to which the following variables were available: seat restraint, parent's sex, marital status, employment, past history of accidents, points on licence, housing, education, journey time, and journey length. Seat restraint entered the model first as the strongest predictor of

Table 2 Associations with seat restraint use

\begin{tabular}{|c|c|c|c|}
\hline & No & $\begin{array}{l}\text { Prevalence } \\
(\%) \text { of seat } \\
\text { restraint }\end{array}$ & $p$ Value * \\
\hline Total & 137 & 85.4 & \\
\hline Sex of parent (male) & 67 & 88.1 & 0.39 \\
\hline Driver & & & $<0.001$ \\
\hline Interviewee & 90 & 92.2 & \\
\hline Interviewee's spouse & 33 & 78.8 & \\
\hline Relative, friend, others & 14 & 57.1 & \\
\hline Journey time & & & $<0.01$ \\
\hline 6 am-12 noon & 77 & 93.5 & \\
\hline 12 noon -6 pm & 49 & 75.5 & \\
\hline $6 \mathrm{pm}-6 \mathrm{am}$ & 11 & 72.7 & \\
\hline Journey length (miles) & & & $<0.05$ \\
\hline$<1$ & 27 & 88.9 & \\
\hline $1-5$ & 36 & 86.1 & \\
\hline $5-10$ & 40 & 90.0 & \\
\hline$\geqslant 10$ & 34 & 76.5 & \\
\hline Marital status & & & $<0.05$ \\
\hline Married & 121 & 87.6 & \\
\hline Other & 16 & 68.8 & \\
\hline Employment & & & 0.091 \\
\hline Full time & 41 & 75.6 & \\
\hline Part time & 37 & 91.9 & \\
\hline $\begin{array}{l}\text { Retired, student, } \\
\text { unemployed }\end{array}$ & 59 & 88.1 & \\
\hline Housing & & & $<0.05$ \\
\hline Own & 90 & 90.0 & \\
\hline Other & 47 & 76.6 & \\
\hline Points on licence & & & $<0.001$ \\
\hline Yes & 23 & 65.2 & \\
\hline No & 114 & 89.5 & \\
\hline
\end{tabular}

${ }^{\star} \mathrm{p}$ Value for null hypothesis that prevalence of seat restraint does not vary according to strata of variables in column 1 . 
Table 3 Logistic regression analysis: odds of being a case

\begin{tabular}{|c|c|c|c|}
\hline & $O R^{\star}$ & $95 \% C I$ & $p$ Valuet \\
\hline Child restrained (yes) & 0.07 & 0.02 to 0.21 & $<0.001$ \\
\hline Sex of parent (male) & 1.23 & 0.58 to 2.57 & 0.590 \\
\hline Driver & & & $<0.01$ \\
\hline Interviewee & 1 & & \\
\hline Interviewee's spouse & 2.75 & 1.17 to 6.48 & \\
\hline Relative, friend, others & 3.74 & 1.17 to 11.96 & \\
\hline Journey time & & & $<0.01$ \\
\hline 6 am-12 noon & 1 & & \\
\hline 12 noon $-6 \mathrm{pm}$ & 5.02 & 2.10 to 12.03 & \\
\hline $6 \mathrm{pm}-6 \mathrm{am}$ & 30.15 & 5.68 to 160.1 & \\
\hline Journey length (miles) & & & $<0.01$ \\
\hline$<1$ & 1 & & \\
\hline $1-5$ & 4.81 & 0.96 to 24.16 & \\
\hline $5-10$ & 6.73 & 1.38 to 2.68 & \\
\hline$\geqslant 10$ & 8.75 & 1.78 to 43.08 & \\
\hline Marital status (married) & 0.65 & 0.22 to 1.93 & 0.44 \\
\hline Employment & & & 0.44 \\
\hline Full time & 1 & & \\
\hline Part time & 0.47 & 0.18 to 1.23 & \\
\hline Retired, student, unemployed & 0.33 & 0.14 to 0.79 & \\
\hline Housing (own) & 0.89 & 0.41 to 1.95 & 0.77 \\
\hline Points on licence (yes) & 5.26 & 2.04 to 13.51 & $<0.001$ \\
\hline No of points (per point) & 1.72 & 1.21 to 2.45 & $<0.001$ \\
\hline No of accidents in 5 years (per accident) & 5.81 & 2.93 to 11.52 & $<0.001$ \\
\hline Age at completion of full time education (years) & & & \\
\hline (per additional year) & 0.97 & 0.88 to 1.08 & 0.62 \\
\hline
\end{tabular}

$\mathrm{OR}=$ odds ratio $\mathrm{CI}=$ confidence interval.

${ }^{\star}$ Comparing case with control.

$t \mathrm{p}$ Value for overall test of association. ney time. The association between injury and journey length may also be spurious because few children attending outpatient clinics in Grampian area will travel more than 10 miles. Because it was not feasible to obtain community based controls in this study, the controls were hospital based, although not selected from attenders to A\&E involved in a road traffic accident, as in previous studies. ${ }^{89}$

While obtaining data on exposures like seat restraint use, there is always a fear that respondents may provide a socially acceptable rather than a truthful response. To try to overcome this problem, we attempted the random response technique. The method proved to be of little help because it has a large random error associated with its estimate of the proportion of parents reporting that their child was restrained. The sample size available to the study was therefore not sufficient to make meaningful interpretations. Furthermore, the estimate of prevalence of seat restraint use obtained by this technique was almost identical to that obtained by the direct method. This suggests that parents may report the correct answer on direct questioning and that information bias may not have been a problem, or that parents give socially acceptable answers even with the random response technique.

The association between the number of accidents incurred by the driver during the past five years, the number of points on the licence, and injury is an important new finding. In this study, a case was defined as a child sustaining an injury, with an MAIS score of $>0$, while travelling in a motor vehicle. All cases will therefore by definition also have been exposed to a motor vehicle accident of some kind. Controls, on the other hand, were children travelling in a motor vehicle and not sustaining an injury. Although it is conceivable that a control child might have been involved in a motor vehicle accident and not have sustained an injury, in fact none of the control children was involved in a car accident. Thus the observed association indicates a relation between previous accident history and the risk of having an accident, and not the risk of sustaining an injury per se. However, this finding of a link between previous accidents and risk of childhood RTAs has important implications for the prevention of accident injury. It suggests that effective strategies aimed at reducing the risk of a further accident among drivers with a history of an accident in the last five years, or with accumulated licence endorsements, might have an additional impact on reducing childhood accident injuries.

The data from this study can be used to estimate the likely minimum and maximum effects (based on the confidence intervals of the odds ratios), in terms of percentage reduction in the incidence of non-fatal injury, of achieving new target levels of seat restraint use. ${ }^{9}$ This kind of information on the marginal benefits of increased seat restraint usage-in terms of expected reductions in death and injurycombined with data on the estimated marginal costs of meeting seat restraint target levels can help policy makers and health service manag- which took place between 9 am and $5 \mathrm{pm}$, and this may wholly or partly explain the strong association observed between injury and jour- 
ers to decide on what extra resources should be allocated to this particular area of health promotion.

We would like to thank all the A\&E staff at Aberdeen Children's Hospital for their help and support. Thanks also to the schools and parents who agreed to participate. This study was funded by the Chief Scientist Office of the Scottish Office Health Department(SOHD); however, the opinions expressed are those of the authors, not the SOHD.

1 Office of Population Censuses and Surveys. Mortality statistics: childhood. England and Wales, 1994. London: HMSO, 1990.

2 Department of Transport. Children and roads: a safer way. London: HMSO, 1990

3 Sharples PM, Storey A, Aynsley-Green A, Eyre JA. Causes of fatal childhood accidents involving head injury in of fatal childhood accidents involving head injur

4 Department of Health. The health of the nation. Key area Department of Health. The health of the natid
handbooks: accidents. London: DOH, 1993.

5 Christopherson E, Sullivan MA. Increasing the protection of newborn infants in cars. Pediatrics 1982;70:21-5.

6 Jarmark S, Ljungblom BA, Turbell T. Infant carriers - a tria in two counties. Linkoping, Sweden: Swedish Road and Traffic Research Institute, 1988. (VTI Report 316A.)
7 Lowne R, Roberts A, Roy AP, et al. The effect of the UK seat restraint legislation on restraint usage by children. Proceedings of the International Congress and Exposition. Technical Paper No 840526. Detroit: Society of Automotive Engineers, 1984

8 Agran P, Dunkle D, Winn D. Effects of legislation on motor vehicle injuries to children. Am f Dis Child 1987;141:95964.

9 Christian MS, Bullimore DW. Reduction in accident injury severity in rear seat passengers using restraints. Injury 1989;20:262-4.

10 Ruta DA, Beattie T, Narayan V. A prospective study of nonfatal childhood road traffic accidents: what can seat fatal childhood road traffic accidents: what can
restraint achieve? F Public Health Med 1993;15:88-92.

11 Department of Transport. Protection of children in cars. Leaflet LF345. Crowthorne, Berkshire: Transport and Road Research Laboratory, 1979.

12 Williams AF, Zador P. Injuries to children in automobiles in relation to seating location and restraint use. Accid Anal Prev 1977;9:69-76.

13 American Association for Automotive Medicine. The abbreviated injury severity scale. Arlington Heights, Illinois: AAAM, 1990.

14 Guntheroth WG, Spiers PS. Bedding and sleeping position in the sudden infant death syndrome. BMF 1990;301:494. 15 Warner SL. Randomised response: a survey technique for eliminating evasive answer bias. F Am Stat Assoc 1965;60: 63-9 